\title{
Serotonin transporter binding of [|23|]ADAM in bulimic women, their healthy twin sisters, and healthy women: a SPET study
} Anu K Koskela*1, Anna Keski-Rahkonen ${ }^{2}$, Elina Sihvola², Tomi Kauppinen ${ }^{3}$, Jaakko Kaprio ${ }^{2,5}$, Aapo Ahonen ${ }^{1}$ and Aila Rissanen ${ }^{4}$

Address: ${ }^{1}$ Department of Clinical Physiology and Nuclear Medicine, HUSLAB/Helsinki University Central Hospital, PL 340, 00029 HUS, Helsinki, Finland, ${ }^{2}$ Department of Public Health, Helsinki University, Helsinki, Finland, ${ }^{3}$ HUS Helsinki Medical Imaging Center, Helsinki University Central Hospital, Helsinki, Finland, ${ }^{4}$ Department of Psychiatry, Helsinki University Central Hospital, Helsinki, Finland and ${ }^{5}$ Department of Mental Health and Alcohol Research, National Public Health Institute, Helsinki, Finland

Email: Anu K Koskela* - anu.koskela@helsinki.fi; Anna Keski-Rahkonen - anna.keski-rahkonen@helsinki.fi; Elina Sihvola - elina.sihvola@helsinki.fi; Tomi Kauppinen - tomi.kauppinen@hus.fi; Jaakko Kaprio - jaakko.kaprio@helsinki.fi; Aapo Ahonen - aapo.ahonen@ hus.fi; Aila Rissanen - aila.rissanen@medi.inet.fi

* Corresponding author

Published: 21 May 2007

BMC Psychiatry 2007, 7:19 doi:10.1186/147/-244X-7-19
Received: 21 September 2006

Accepted: 2I May 2007

This article is available from: http://www.biomedcentral.com/I47I-244X/7//9

(c) 2007 Koskela et al; licensee BioMed Central Ltd.

This is an Open Access article distributed under the terms of the Creative Commons Attribution License (http://creativecommons.org/licenses/by/2.0), which permits unrestricted use, distribution, and reproduction in any medium, provided the original work is properly cited.

\begin{abstract}
Background: Bulimia Nervosa (BN) is believed to be caused by an interaction of genetic and environmental factors. Previous studies support the existence of a bulimia-related endophenotype as well as disturbances in serotonin $(5-\mathrm{HT})$ transmission. We studied serotonin transporter (SERT) binding in BN, and to investigate the possibility of a SERT-related endophenotype for BN, did this in a sample of female twins. We hypothesized clearly reduced SERT binding in BN women as opposed to healthy women, and intermediate SERT binding in unaffected co-twins.
\end{abstract}

Methods: We studied 13 female twins with $\mathrm{BN}$ (9 with purging and 4 with non-purging $\mathrm{BN}$ ) and 25 healthy women, including 6 healthy twin sisters of BN patients and 19 women from 10 healthy twin pairs. ['23|]ADAM, a selective SERT radioligand for single photon emission tomography (SPET) imaging, was used to assess SERT availability in the midbrain and the thalamus.

Results: No differences in SERT binding were evident when comparing the BN women, their unaffected co-twins and the healthy controls $(p=0.14)$. The healthy sisters of the BN patients and the healthy control women had similar SERT binding in both brain regions. In a post hoc subgroup analysis, the purging bulimics had higher SERT binding than the healthy women in the midbrain ( $P$ $=0.03)$, but not in the thalamus.

Conclusion: Our finding of increased SERT binding in the midbrain in the purging BN women raises the possibility that this subgroup of bulimics might differ in serotonergic function from the non-purging ones. The similarity of the unaffected co-twins and the healthy controls doesn't support our initial assumption of a SERT-related endophenotype for BN. Due to the small sample size, our results need to be interpreted with caution and verified in a larger sample.

\section{Background}

Bulimia Nervosa $(\mathrm{BN})$ is a common eating disorder that predominantly affects young women. It is characterized by body image distortions and episodes of excessive eat- 
ing, followed by compensatory behaviors, such as strict dieting, vomiting, laxative misuse or compulsive exercise [1]. BN is often accompanied by disturbances of mood and impulse control [2].

The neurotransmitter serotonin (5-HT), involved in the regulation of eating behavior [3], may play a role in the pathophysiology of BN. Subjects with symptomatic BN show several abnormalities in 5-HT metabolism and function [4-9]. Both women with current BN and women who have recovered from $\mathrm{BN}$ seem more vulnerable than healthy control women to the mood lowering and the binge precipitating effects of acute tryptophan depletion $[10,11]$. A wide range of antidepressant medications are effective in reducing binge and purge frequency $[12,13]$.

It is uncertain whether the changes in 5-HT system in BN are trait dependent (i.e., representing a predisposition to an illness) or state dependent (i.e., resulting from changes in nutritional status during an acute illness). There is some evidence suggesting a bulimia-related endophenotype, such as premorbid anxiety symptoms [14] as well as serotonergic alterations that remain after recovery $[11,15,16]$. Evidence from family and twin studies suggests a genetic contribution to the etiology of eating disorders [17], but consistent evidence of genetic variation specifically affecting serotonin metabolism disturbances in $\mathrm{BN}$ is lacking. Twin samples offer an opportunity to explore state and trait related differences, given that the healthy twins share either all or half their segregating genes with their affected co-twin, depending on whether the twin pair is monozygotic (MZ) or dizygotic (DZ). Moreover, twins are of the same age and have generally similar childhood and adolescent experiences. Observed differences between women with $\mathrm{BN}$ and their sisters are likely due to state effects, whereas differences observed between healthy twin sisters and unrelated controls would be trait-related.

The recent developments of new radioligands for various neurotransmitter systems for positron emission tomography (PET) and single photon emission tomography (SPET) imaging have enabled more direct, in vivo studies of neurotransmitter dysfunction in different conditions. Previous studies have suggested reduced availability of brain serotonin transporters (SERTs) in BN [18] and Binge Eating Disorder (BED) [19]. There are reports on increased $5-\mathrm{HT}_{1 \mathrm{~A}}$-binding in $\mathrm{BN}[20]$ as well as on reduced 5 - $\mathrm{HT}_{2 \mathrm{~A}}$-binding in women who have recovered from $\mathrm{BN}$ [16] and from bulimia-type Anorexia Nervosa [21].

Iodine 123-labeled 2-((2-((dimethylamino)methyl)phenyl)thio)-5-iodophenylamine ([123I]ADAM) is a selective radioligand for SPET imaging of SERTs. Its affinity to SERTs is more than 1000 -fold over its affinity to dopamine transporters and norepinephrine transporters [22]. Its binding is greatest $[23,24]$ and least variable in a test-retest setting in the midbrain and the thalamus [23], and reaches a pseudoequilibrium at 4-6 $\mathrm{h}$ post injection [23]. Its effective dose is similar to the other commonly used radioligands $[25,26]$. We have previously created an [123I]ADAM brain template and a predefined VOI (volume of interest) map for the automated registration and analysis of the [ $\left.{ }^{123} \mathrm{I}\right]$ ADAM images [27].

The aim of this study was to (1) investigate whether the finding of reduced SERT binding in subjects with BN observed using the less selective radioligand $\left[{ }^{123} \mathrm{I}\right] \beta$-CIT [18] can be replicated with [123I]ADAM, and (2) to explore the possible genetic background of $\mathrm{BN}$ by comparing [123I]ADAM binding to SERTs between subjects with $\mathrm{BN}$, their healthy co-twins and healthy controls. We assumed that SERT transmission is a bulimia-related endophenotype, i.e., a heritable quantitative trait that is state-independent (manifest in the individual whether or not illness is active), and found more often in unaffected family members than in the general population. Therefore, we hypothesized that SERT availability would be clearly reduced in SERT rich brain areas in BN women compared to unaffected women, and that the SERT availability of unaffected co-twins would be intermediate between that of probands and healthy women.

\section{Methods}

\section{Study participants}

The study participants were recruited from FinnTwin16, a population-based, longitudinal study including virtually all Finnish twins born 1975-1979 and first studied at the age of 16 [28]. At the age of 22-27 years, the 2545 female twins were screened for eating disorders by self-report questionnaire: 292 screen-positive women, their 130 female co-twins, and 210 screen-negative women were then interviewed using a short version of the SCID-I interview [29] (interview participation rate 85.2\%) [30]. From the interviews, we obtained lifetime diagnoses of anorexia, bulimia, binge eating disorder, major depression (MDD) and obsessive-compulsive disorder (OCD). All women suffering from $\mathrm{BN}$ who were not on current serotonergic medication $(\mathrm{n}=13)$ as well as their female cotwins were invited to participate in the [123I]ADAM study. The DSM-IV diagnosis of bulimia nervosa of each case detected was further confirmed with semi-structured EATATE [31] and SSAGA interviews $[32,33]$. We chose to also include two women recently recovered from $\mathrm{BN}$ in this group on the basis of the evidence suggesting a trait for $\mathrm{BN}$.

Ten healthy, medication-free control female twin pairs without bulimic symptoms were selected from the same FinnTwin16 cohort and invited to participate in the 
[123I]ADAM study. They were also assessed with EATATE and SSAGA interviews, which ruled out past or present eating disorders and revealed one case with a former history of depression. We thus excluded her from our study. Another healthy control was excluded due to an unsuccessful [123I]ADAM injection.

In the present analysis, we have included:

1. 13 twin women fulfilling lifetime DSM IV criteria for BN, including 7 women from discordant twin pairs (1 MZ pair and $6 \mathrm{DZ}$ pairs) and 6 women from concordant twin pairs (2 $\mathrm{MZ}$ and $1 \mathrm{DZ}$ ).

2. 25 healthy twin women, including 6 healthy twin sisters of the women with BN ( $1 \mathrm{MZ}$ and $5 \mathrm{DZ}$ ) and 18 women from 10 (5 MZ and $5 \mathrm{DZ}$ female-female) healthy twin pairs.

All the study subjects were free from psychotropic medication at the time of the study. 4 women with BN had previously been on selective serotonin reuptake inhibitor (SSRI) medication, but had been drug-free for more than 1 year before the study.

The zygosity of all twin pairs was confirmed by genetic blood marker studies using the highly polymorphic, multiple genetic marker set used in the Paternity testing laboratory, National Public Health Institute, Helsinki, Finland.

After complete description of the study procedures to the subjects, written informed consent according to the Declaration of Helsinki was obtained from all participants. The Ethics Committees of Kuopio University Hospital and Helsinki University Central Hospital approved the study.

\section{Radiopharmaceutical}

The radioligand [123I]ADAM [22] (MAP Medical Technologies Oy, Tikkakoski, Finland) was used for imaging of brain serotonin transporters. Thirty minutes before its intravenous injection, the subjects were given $400 \mathrm{mg}$ of potassium perchlorate orally to reduce [123I]-uptake in the thyroid and the salivary glands. Injected radioactivity of [123I]ADAM varied between 139-231 MBq.

\section{SPET imaging and image reconstruction}

The SPET scannings took place 5 hours after the injection of [123I]ADAM with a Philips Picker Prism3000XP threeheaded gamma camera with ultra-high-resolution fanbeam collimators (Philips Medical Systems, Cleveland, OH, USA). The fan-beam focus of the collimator was 535 $\mathrm{mm}$. We used 120 degree orbit in a stepwise mode and a symmetrical energy window (159 keV; 20\% wide, 143 $\mathrm{keV}-175 \mathrm{keV})$. The radius of rotation varied between 130
$160 \mathrm{~mm}$, depending on the patient. The subjects' heads were positioned with a crossed laser beam system to the centre of rotation. Scans were acquired with a $128 \times 128$ matrix size using 120 projection angles (40 projections/ detector). The acquisition time was $45 \mathrm{~s}$ per projection angle, resulting in an average of 20 kcts.

All reconstructions and image analyses were done on a HERMES software system (Hermes Medical Solutions, Stockholm, Sweden). The images were reconstructed iteratively ( 8 subsets with 6 iterations) using HOSEM (OSEM V5.201 by R. Larkin) and transverse slices were reconstructed. Attenuation correction (Chang's first-order approximation) was performed using the linear attenuation correction $\left(\mu=0.110 \mathrm{~cm}^{-1}\right)$. Butterworth filter with cut-off frequency of $1.2 \mathrm{~cm}^{-1}$ and order 15 was used for post-filtering of the images.

\section{Quantification of SERT availability}

We have previously created a brain template with a predefined volume of interest (VOI) map for [123I]ADAM images using BRASS (Brain Registration and Analysis of SPECT Studies) software (Hermes Medical Solutions, Stockholm, Sweden) on a HERMES workstation [27]. We used this template as a basis for automated registration and realignment of the scans done for the subjects in the study. The anatomically standardized (stereotactic) images were used for automated VOI quantification. SERT availability was assessed in VOIs of fixed size of the midbrain, the thalamus and the cerebellum, which was used as a reference region [34] (Figure 1.). We chose to restrict the data analyses to these regions on the basis of the previous data showing the greatest SERT binding and the least test-retest variability in the midbrain and the thalamus [23]. The voxel size was $2 \times 2 \times 2 \mathrm{~mm}$ and the slice separation $4 \mathrm{~mm}$. Both the midbrain and the thalamus VOIs were placed on 2 consecutive slices and consisted alltogether of 94 (midbrain) and 386 (thalamus) voxels. The cerebellum VOI was placed on 3 consecutive slices and consisted of 1806 voxels. As the location of the midbrain activity varied a little between the subjects, more than the location of the thalamus activity, we chose to alter the position of the midbrain VOI manually, if it did not seem correct. This was done without altering the size of the VOI or the level (slice) on which the VOI was positioned by the automated procedure. All image reconstructions, registrations to the template and possible moving of the midbrain VOIs were performed by a nuclear medicine physician, who was blind to subject identity and diagnosis.

SERT binding was estimated by using the formula Specific Binding Ratio $(\mathrm{SBR})=($ mean counts in the target area mean counts in cerebellum)/mean counts in cerebellum. This model has been shown to correlate well with the 


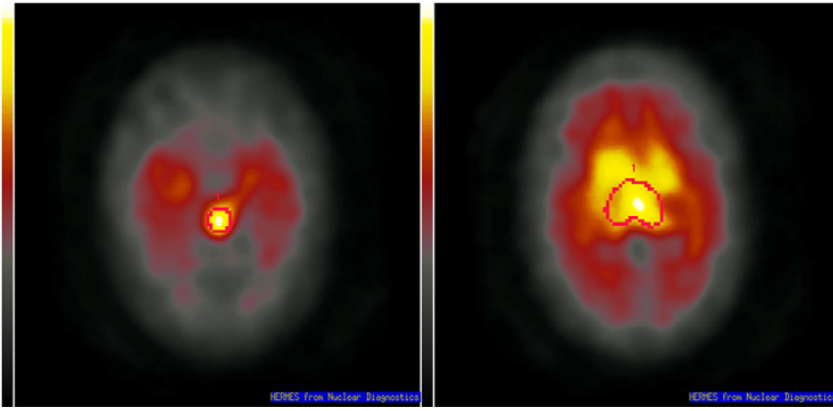

Figure I

The [ $\left.{ }^{123} \mid\right]$ ADAM template (mean image of scans of I 5 healthy women) and the midbrain (left) and thalamus (right) volumes of interest.

graphical analysis with arterial plasma input for [ ${ }^{123}$ I]ADAM-studies [35]. Half-life correction was done for calculated SBR values.

Non-specific uptake was quantified by dividing the mean counts/pixel of the cerebellar VOI by the injected activity.

\section{Statistical analysis}

The data were analyzed using the Stata software (release 8.2; Stata Corp., College Station, TX, USA). If needed, the variables were log transformed to normalize their distribution.

In accordance with our study objective of examining the possible (genetic) differences of state and trait dependent SERT binding, we distinguished 3 groups of subjects: BN women, their healthy female co-twins and unrelated controls. State differences would be revealed by observed differences between BN women and their co-twins, whereas any differences observed between healthy co-twins and unrelated controls would be due to trait effects, given that the healthy co-twins share childhood experiences as well as at least half of their segregating genes with their affected co-twin. Our sample size did not permit us to do analyses by zygosity.

First, we compared all the twins as individuals. When twins are analyzed as individuals rather than as pairs, the observations and their error terms between members of a pair may be correlated. Therefore, to account for individuals nested within twin pairs, we used techniques derived from hierarchical linear modeling to adjust for clustering of twins within twin pairs. For comparison of the three groups, i.e. the diseased subjects, their healthy co-twins and the healthy control twin pairs we used one-way analysis of variance, and then appropriate two-group tests. Multiple linear regression analyses were used to test the effects of multiple explanatory variables on a response variable. In Stata, the procedures SVYMEAN, SVYTEST and SVYREG permit derivation of the proper standard errors, variances, confidence intervals and $P$ values, correcting for dependency within a twin pair.

Second, we made within-pair comparisons to test the significance of intra-pair differences in SERT binding in twin pairs discordant for $\mathrm{BN}$ and in healthy twin pairs by using the paired nonparametric Wilcoxon test. Third, we compared the mean intrapair difference in SERT binding between twin pairs discordant for $\mathrm{BN}$ and healthy control twins by using the nonparametric Mann-Whitney U-test.

We also performed a post hoc analysis of the purging BN women against all the healthy women combined. This decision was based on the clinical observation that purging bulimia is often more severe in its course as compared to non-purging type bulimia. Further post hoc analyses were done on the effects of psychiatric co-morbidities on study results.

Data are shown as mean \pm standard deviation. P values less than 0.05 were considered statistically significant.

\section{Results}

Demographic variables and behavioral assessments

The mean body mass indices (BMIs) and ages were similar for the 13 women with $\mathrm{BN}$, their twin sisters and the healthy control twins (Table 1.) The mean age of onset of bulimia was 18.3 y (SD: 2.9 y, range: $13-21$ y) and its mean duration was $6.5 \mathrm{y}$ (SD: $4.4 \mathrm{y}$, range: 6 months -14 $y)$. Of the 2 subjects with lifetime $\mathrm{BN}$, one had been asymptomatic for 3 and the other for 5 years. 9 of the 13 bulimic individuals suffered from the purging subtype of $\mathrm{BN}$, and 4 were diagnosed with the non-purging subtype of $\mathrm{BN}$. Compensatory behaviors other than vomiting included diuretics and Ipecac abuse, excessive exercise, and fasting. 5 individuals had a past history of anorexic symptoms, but had been free from anorectic symptoms for more than 6 months prior to our study.

There was 1 case with present and 7 cases with past history of major depressive disorder (MDD) in the $\mathrm{BN}$ group. None of the healthy sisters or healthy control women suffered from present MDD. One healthy control with a past history of MDD was excluded from the study.

\section{SERT availability in volumes of interest}

The specific binding ratios of [123I]ADAM to SERTs in the midbrain and the thalamus are shown in Table 2. SERT binding was similar for the groups of BN probands, their unaffected sisters and healthy control women in both the midbrain $(p=0.14)$ and the thalamus $(p=0.85)$. The unaffected sisters did not differ from the healthy controls in neither the midbrain $(\mathrm{p}=0.66)$ nor the thalamus $(\mathrm{p}=$ 
0.66), and therefore we combined these two groups of healthy women. No significant differences were found in comparison of the BN women and all the healthy women combined (Table 3.). Removal of the 2 currently unsymptomatic women from the group of probands did not affect these results (data not shown). In a post hoc analysis, the subgroup of purging bulimic women differed significantly in their SERT binding from the healthy women in the midbrain $(\mathrm{p}=0.03)$ but not in the thalamus $(\mathrm{p}=0.35)$ (Table 3.).

In further post hoc analyses, we investigated the effect of MDD and past history of AN on the results. SBRs in the midbrain and the thalamus were similar for the subjects with $(\mathrm{n}=7)$ and without $(\mathrm{n}=30)$ a history of MDD (in the midbrain: $\mathrm{SBR}_{\mathrm{MDD}} 2.20 \pm 0.22, \mathrm{SBR}_{\mathrm{no}-\mathrm{MDD}} 2.10 \pm 0.30$, $\mathrm{p}=0.38$, and in the thalamus: $\mathrm{SBR}_{\mathrm{MDD}} 1.48 \pm .28, \mathrm{SBR}_{\mathrm{no}}$ MDD $1.42 \pm .26, \mathrm{p}=0.63$ ). Regarding past AN, the mean SBRs for SERT binding were very similar for the BN women with $(\mathrm{n}=5)$ and without $(\mathrm{n}=8)$ past history of AN (in the midbrain: $\mathrm{SBR}_{\mathrm{AN}} 2.25 \pm 0.26, \mathrm{SBR}_{\mathrm{no}-\mathrm{AN}} 2.21 \pm$ 0.22 , and in the thalamus: $\mathrm{SBR}_{\mathrm{AN}} 1.50 \pm 0.28, \mathrm{SBR}_{\mathrm{no}-\mathrm{AN}}$ $1.42 \pm 0.21)$. In multiple linear regression analysis, history of MDD or AN had no effect on the results, whereas the effect of purging remained significant (Table 4).

In within-pair comparisons, there were no differences in SBRs between a twin and her co-twin in either of the brain regions in neither the group of twins discordant for BN (n $=6$ pairs $)$ nor the healthy twin pairs $(\mathrm{n}=9$ pairs $)$. The means of intrapair differences for SBRs (SBR of twin 1-SBR of twin 2 in a given area) were also similar for the discordant twin pairs and the healthy control twin pairs in both the midbrain and the thalamus regions. Within-pair comparisons were not done for the pairs discordant for purging lifetime $\mathrm{BN}$ as we had only two such pairs.

SERT binding in the cerebellum (i.e., non-specific uptake) did not differ between the groups (98.99 \pm 17.53 counts/ $\mathrm{pixel} / \mathrm{kBq}$ for the subjects with lifetime BN, $93.38 \pm 21.42$ counts/pixel $/ \mathrm{kBq}$ for the healthy co-twins and $96.52 \pm$ 15.26 counts $/ \mathrm{pixel} / \mathrm{kBq}$ for the healthy controls, $\mathrm{p}=$ $0.73)$.

\section{Discussion}

In this study, we examined the binding of a SERT-specific radioligand [123I]ADAM to the midbrain and the thala- mus of women with bulimia nervosa, their healthy female co-twins and healthy controls. Against our initial hypothesis, we found no differences in SERT binding between the three study groups. However, in a post hoc analysis we observed increased SERT binding in the midbrain in the purging $\mathrm{BN}$ women. Our work extends the previous literature on the role of serotonergic pathways in the etiology of $\mathrm{BN}[36]$ and suggest differences in SERT function between the purging and the non-purging $\mathrm{BN}$ women. Our findings do not support the existence of a bulimiarelated endophenotype.

The involvement of serotonergic system in $\mathrm{BN}$ has been suggested in a number of studies. Examples include blunted plasma hormonal response to drugs with 5-HT activity [5], worsening of symptoms after dietary depletion of tryptophan (precursor of 5-HT) [10], the beneficial effect of antidepressant medications in BN $[12,13]$, and differences found in brain PET- and SPET-studies in SERTs [18] and $5-\mathrm{HT}_{1 \mathrm{~A}}$-receptors [20]. Furthermore, some disturbances of serotonergic system, such as vulnerability to the effects of tryptophan depletion [11] and elevation of cerebrospinal fluid concentration of 5-HT metabolite 5hydroxyindolacetic acid (5-HIAA) [15], seem to persist after recovery. Alterations after recovery have also been found in the imaging studies of $5 \mathrm{HT}_{2 \mathrm{~A}}$-receptors [16].

There are several possible explanations to our failure to find differences of SERT binding between the whole group of bulimics and the healthy subjects. First, there may be alterations of SERT function in other brain regions than were investigated in our study. Some existing data from functional magnetic resonance imaging studies suggest alterations in the lateral fusiform gyrus, the inferior parietal cortex, and the lateral prefrontal cortex [37]. PET and SPET studies with $5-\mathrm{HT}_{1 \mathrm{~A}}$ and $5-\mathrm{HT}_{2 \mathrm{~A}}$ ligands have found changes in the the frontal, parietal and cingulate areas [36]. As the binding of [123I]ADAM is scant and less reliable in these regions [23], we did not investigate them in our study. Second, the disturbances of serotonergic function in BN may not be found in SERTs, but instead in other parts of the serotonergic system. Two previous studies have suggested alterations in $5-\mathrm{HT}_{2 \mathrm{~A}}$ and $5-\mathrm{HT}_{1 \mathrm{~A}}$-receptors $[20,21]$. Even though the SSRIs have been shown to be useful in the treatment of $\mathrm{BN}[38]$, it does not necessarily indicate a disturbance of SERT function in $\mathrm{BN}$, as the mechanism of action of the SSRIs is not believed to be

Table I: Study subjects' ages and BMIs

\begin{tabular}{lllll}
\hline & Bulimics $(\mathbf{n}=\mathbf{~ 1 3 )}$ & Twin-sisters $(\mathbf{n}=\mathbf{6})$ & Controls $(\mathbf{n}=\mathbf{~ 1 8})$ & P* \\
\hline BMI $\left(\mathbf{k g} / \mathbf{m}^{2}\right)$ & $22.9 \pm 3.2$ & $23.6 \pm 3.2$ & $22.2 \pm 3.5$ & 0.68 \\
Age (years) & $24.8 \pm 1.7$ & $24.8 \pm 2.1$ & $25.3 \pm 1.7$ & 0.81 \\
\hline
\end{tabular}

*Significant differences between the groups were calculated using ANOVA: p-values were corrected for clustered sampling. 
Table 2: SBRs for women with lifetime BN, their healthy co-twins and healthy control women

\begin{tabular}{lllll}
\hline & Women with lifetime BN $(\mathbf{n}=\mathbf{~ I 3 )}$ & Healthy co-twins $(\mathbf{n}=\mathbf{6})$ & Healthy control women $(\mathbf{n}=\mathbf{~ I 8 )} \quad$ P* \\
\hline Midbrain & $2.23 \pm 0.22$ & $2.02 \pm 0.29$ & $2.07 \pm 0.31$ & 0.21 \\
Thalamus & $1.45 \pm 0.23$ & $1.38 \pm 0.25$ & $1.43 \pm 0.29$ & 0.86 \\
\hline
\end{tabular}

*ANOVA, correction for dependency within twin pairs

direct effect on SERT or increased synaptic 5-HT [39]. Desensitization of somatodendritic $5-\mathrm{HT}_{1 \mathrm{~A}}$ autoreceptors in the midbrain raphe nucleus is one suggested mechanism; this would increase 5-HT in critical brain regions and at key receptor subtypes [40-43]. Third, there is also a possibility of impairments outside but in connection to the serotonergic system. According to one theory, 5-HT acts as a modulator in the homeostasis between dopamine, noradrenalin and GABA. Serotonergic drugs might help reinstate the homeostasis of this system [44]. Another suggested mechanism of action of the SSRIs is the potentiation of neurogenesis [45].

There is also the possibility that the inclusion of the two currently unsymptomatic BN women diluted the differences between the probands and the healthy women. Their inclusion was based on our initial hypothesis of a bulimia-related endophenotype. As we later observed, our results on the unaffected co-twins do not support the idea of a SERT associated endophenotype for BN. However, removal of these two women from the probands did not change our findings.

It is also possible that $\mathrm{BN}$ may in fact include biologically distinct subgroups. Purging bulimics have been found to differ from non-purging ones in certain personality variables (e.g. lower self-directedness, organization, personal standards, and higher novelty seeking) [46]. Our results point towards a difference of SERT function between these two subgroups, given that only the subjects with a purging-subtype of BN differed significantly from the healthy subjects in the midbrain SBRs. As this is a finding of a post hoc analysis and made in a small study sample, it needs to be confirmed in other studies.

There are some important differences between the present study and the previous study on SERT binding in BN [18]. The radioligand previously used was $\left[{ }^{123} \mathrm{I}\right] \beta-\mathrm{CIT}$, which binds to DATs and NETs as well as to SERTs [47-49], leaving a possibility that its binding to NETs in the thalamus has affected the findings. Another difference lies at the study groups. It is possible that our BN cases, identified from a population-based twin cohort, were different to the clinic-based cases in the previous study. Thus, treatment seeking characteristics, disease severity and other differences between the study groups may to a point explain the differences between these two studies. Also, the exclusion of cases with psychotropic medication from our study probably shifts the balance towards clinically less complex cases.

In our study, SERT binding was similar in the healthy cotwins of the bulimics and the other healthy women. It is not known whether the previously reported alterations of 5 -HT function after recovery $[11,15,16]$ represent "scarring" caused by $\mathrm{BN}$ or a disturbance of 5-HT function that is present before the actual symptoms, predisposing a subject for BN. The reported premorbid anxiety symptoms [14] suggest presence of vulnerability for BN and the evidence from family and twin studies suggests a genetic contribution to etiology of eating disorders [17]. If such a genetic trait (i.e., endophenotype) exists in SERT function, it should be evident in the unaffected co-twins of the $\mathrm{BN}$ probands. Our finding of similarity of SERT binding between the co-twins and the other healthy women is against our initial hypothesis and does not support the existence of a SERT-related trait for BN. However, the small number of the unaffected co-twins reduces the reliability of this conclusion and also prevented analyses separately by zygosity. The number of unaffected co-twins of the purging bulimics $(n=2)$ was even smaller: therefore, we cannot make assumptions on whether the observed increase in SERT binding in the purging BN women is a state- or trait-related increase in SERT binding.

Table 3: SBRs: Comparison of all healthy women with all BN women and the subgroup of purging BN women

\begin{tabular}{|c|c|c|c|c|c|}
\hline & Women with lifetime $B N(n=13)$ & All healthy women $(n=24)$ & Women with purging BN $(n=9)$ & $\mathbf{P} *$ & $\mathbf{P} * *$ \\
\hline Midbrain & $2.23 \pm 0.22$ & $2.06 \pm 0.30$ & $2.26 \pm 0.19$ & 0.08 & 0.03 \\
\hline Thalamus & $1.45 \pm 0.23$ & $1.42 \pm 0.28$ & $1.50 \pm 0.25$ & 0.73 & 0.45 \\
\hline
\end{tabular}

* Women with lifetime $\mathrm{BN}$ vs. all healthy women. t-test, correction for dependency within twin pairs

** Women with lifetime purging $\mathrm{BN}$ vs. all healthy subjects. t-test, correction for dependency within twin pairs 
Table 4: Multiple regression analysis examining the relationship of SERT binding with purging BN and past histories of Major Depression and Anorexia Nervosa

\begin{tabular}{|c|c|c|c|}
\hline MIDBRAIN: $R^{2}=0.10, F(3, I 7)=3.92, p=0.03$ & $\beta$ & S.E. of $\beta$ & p-value \\
\hline Purging BN & -.22 & .09 & .02 \\
\hline History of major depression & .08 & .10 & 0.44 \\
\hline History of AN & -.08 & .09 & 0.38 \\
\hline THALAMUS: $R^{2}=0.03, F(3,17)=1.02, p=0.41$ & $\beta$ & S.E. of $\beta$ & p-value \\
\hline Purging BN & -.10 & .06 & 0.14 \\
\hline History of major depression & .02 & .09 & 0.80 \\
\hline History of AN & -.04 & .12 & 0.72 \\
\hline
\end{tabular}

Correction for dependency between twin pairs done for

Our results differed from the initial hypothesis also in the direction of the difference in SERT binding. Our initial hypothesis was reduced SERT binding in BN: however, what we found was increased SERT binding in the purging probands. Many studies suggest reduced 5-HT transmission in BN $[4-10,16,18]$. Also in many (but not all) SPET and PET studies, reduced SERT binding has been interpreted to indicate reduced 5-HT function. However, this assumption may not necessarily be true. Theoretically, reduced intrasynaptic 5-HT could lead to increased binding of the radioligand due to 1) less competition for the binding sites or 2) compensatory increase in the amount of SERT on the nerve terminals. Alternatively, reduced 5HT could reduce SERT binding if the amount of SERTs on nerve terminals is reduced due to increased internalization of SERTs [50]. Recent PET studies with the SERT ligand ${ }^{11} \mathrm{C}$-DASB have assessed the effects of artificial alterations of intrasynaptic 5-HT. The findings to date are inconsistent, with reports of either decreased [51] or unchanged [52] SERT binding after decrease in intrasynaptic 5-HT or decreased binding after increase in intrasynaptic 5-HT [53]. The true nature of the relationship of intrasynaptic 5-HT concentration and SERT binding is thus yet to be discovered. Furthermore, not only the amount of intrasynaptic 5-HT but also disease specific alterations in number and affinity of SERTs can affect SERT binding. Therefore, we don't really know the true interpretation of our findings: we can only state that we found a difference in a direction opposite from our original hypothesis.

There are some limitations to our study. Our sample size is smaller than we initially aimed for. Even though we screened thousands of twins, the number of BN probands was smaller than we expected. The presence of three concordant pairs also reduced the number of the unaffected co-twins, limiting our ability to make conclusions on the endophenotype concept. One factor that clearly reduced the number of our cases was the exclusion of subjects with antidepressant medication. We acknowledge the limited power of our study and the considerable probalility of both type one (due to multiple comparisons) and type two (due to small sample size) errors. Furthermore, the inclusion of subjects with past histories of MDD and AN are possible confounds. These conditions often co-exist and exclusion of probands with past history of MDD or AN would have made our study sample even smaller. However, in post hoc analyses, neither of these conditions had effect on our results.

We did not control for phase of menstrual cycle, which has been implicated as source of variation in SERT binding [54]. However, a recent study with [ ${ }^{123}$ I]- $\beta$-CIT found no such effect [55]. On the other hand, we could fully exclude variation due to sex and age by including only females within a narrow age-range.

The radiotracer [123I]ADAM might have some properties that affect its usefulness in SERT imaging. The reported intra-subject test-retest variability of [123I]ADAM binding is $13 \%$ in midbrain and $16 \%$ in thalamus, which is, however, of the same magnitude as for other SERT SPET ligands [23]. There is also a report on lipophilic metabolites of [123I]ADAM [35], which, if present, might also affect our findings. We also can not exclude the possibility of different metabolism of [123I]ADAM between patients and healthy subjects as we did not do blood screening of its metabolism. The cerebellar activity, which mostly represents non-spesific binding of [123I]ADAM, did not differ between the groups.

Our template based realignment and fitting procedure is objective and repeatable, but may lead to some small errors of VOI placement and also dilute or emphasize some effects. However, this method was most suitable for our study as Magnetic Resonance Imaging (MRI) - based VOI definition was prevented by some of our subjects having contraindications for MRI. We tried to minimize the VOI placement errors by manually moving the midbrain- 
VOI of fixed size within the fixed brain level, when necessary.

In summary, our results do not support the initial assumption of decreased SERT binding in $\mathrm{BN}$ or the existence of a SERT-related endophenotype for BN. Instead, the increased SERT binding in the midbrain of purging bulimics observed in this study suggests that the involvement of SERT function in this type of BN is stronger than in non-purging BN and differs from healthy subjects. However, due to small sample size and confounding factors our results need to be taken with caution and verified in larger samples of clinical BN cases.

\section{Competing interests}

The author(s) declare that they have no competing interests.

\section{Authors' contributions}

AK carried out and analysed the SPET studies, performed statistical analyses and was the main author of the manuscript.

AK-R and ES participated by planning the study design, in selecting the study subjects, and doing the psychiatric assessments, and by commenting on, revising and approving the manuscript.

TK participated by planning the SPET protocol and quantification of the SPET studies, commenting on, revising and approving the manuscript.

JK participated by collecting the Finnish Twin Cohort data, in planning of the BN study, and by commenting on, revising and approving the manuscript.

AA participated by planning the SPET protocol, commenting on, revising and approving the manuscript.

AR participated by planning the study design, commenting on, revising and approving the manuscript.

All the authors have read and approved the final manuscript.

\section{Acknowledgements}

The authors thank Dr. Markus Diemling from Hermes Medical Solutions, Stockholm, Sweden, for the help in the creation of [123/]ADAM template, Mr. Timo Lukkarinen for providing the MR images, Erjastiina Heikkinen for assisting in scheduling the study subjects, and all the twins who participated this study.

This work was supported by the USPHS National Institute of Alcohol Abuse and Alcoholism (AA083 15, AA 12502), the European Union Fifth Framework Program (QLRT-1999-00916, QLG2-CT-2002-01254), Academy of Finland grants, the Academy of Finland Center of Excellence in
Complex Disease Genetics, and Helsinki University Central Hospital grants and A.K. by Research Foundation of the Orion Corporation.

\section{References}

I. American Psychiatric Association: DSM IV: diagnostic and statistical manual of mental disorders 4th edition. Washington, DC, American Psychiatric Association; 1994.

2. Kaltiala-Heino R, Rissanen A, Rimpela M, Rantanen P: Bulimia and impulsive behaviour in middle adolescence. Psychother Psychosom 2003, 72:26-33.

3. Leibowitz SF, Alexander JT: Hypothalamic serotonin in control of eating behavior, meal size, and body weight. Biol Psychiatry 1998, 44:85 I-864.

4. Goldbloom DS, Hicks LK, Garfinkel PE: Platelet serotonin uptake in bulimia nervosa. Biol Psychiatry 1990, 28:644-647.

5. Goldbloom DS, Garfinkel PE, Katz R, Brown GM: The hormonal response to intravenous 5-hydroxytryptophan in bulimia nervosa. J Psychosom Res 1996, 40:289-297.

6. Jimerson DC, Lesem MD, Kaye WH, Brewerton TD: Low serotonin and dopamine metabolite concentrations in cerebrospinal fluid from bulimic patients with frequent binge episodes. Arch Gen Psychiatry 1992, 49: I32-I38.

7. Jimerson DC, Wolfe BE, Metzger ED, Finkelstein DM, Cooper TB, Levine JM: Decreased serotonin function in bulimia nervosa. Arch Gen Psychiatry 1997, 54:529-534.

8. Kaye WH, Ballenger JC, Lydiard RB, Stuart GW, Laraia MT, O'Neil P, Fossey MD, Stevens V, Lesser S, Hsu G: CSF monoamine levels in normal-weight bulimia: evidence for abnormal noradrenergic activity. Am J Psychiatry 1990, 147:225-229.

9. Kaye W, Gendall K, Strober M: Serotonin neuronal function and selective serotonin reuptake inhibitor treatment in anorexia and bulimia nervosa. Biol Psychiatry 1998, 44:825-838.

10. Kaye WH, Gendall KA, Fernstrom MH, Fernstrom JD, McConaha CW, Weltzin TE: Effects of acute tryptophan depletion on mood in bulimia nervosa. Biol Psychiatry 2000, 47: 15 I-I57.

II. Smith KA, Fairburn CG, Cowen PJ: Symptomatic relapse in bulimia nervosa following acute tryptophan depletion. Arch Gen Psychiatry 1999, 56:171-I76.

12. Mitchell JE, Raymond N, Specker S: A review of the controlled trials of pharmacotherapy and psychotherapy in the treatment of bulimia nervosa. Int J Eat Disord 1993, I 4:229-247.

13. Walsh BT: Psychopharmacologic treatment of bulimia nervosa. J Clin Psychiatry 199I, 52(Suppl):34-38.

14. Kaye WH, Bulik CM, Thornton L, Barbarich N, Masters K: Comorbidity of anxiety disorders with anorexia and bulimia nervosa. Am J Psychiatry 2004, I 6 I:221 5-2221.

15. Kaye WH, Greeno CG, Moss H, Fernstrom J, Fernstrom M, Lilenfeld LR, Weltzin TE, Mann JJ: Alterations in serotonin activity and psychiatric symptoms after recovery from bulimia nervosa. Arch Gen Psychiatry 1998, 55:927-935.

16. Kaye WH, Frank GK, Meltzer CC, Price JC, McConaha CW, Crossan $\mathrm{PJ}$, Klump KL, Rhodes L: Altered serotonin 2A receptor activity in women who have recovered from bulimia nervosa. $\mathrm{Am} J$ Psychiatry 200I, I 58: I I 52-I I55.

17. Bulik CM, Sullivan PF, Wade TD, Kendler KS: Twin studies of eating disorders: a review. Int J Eat Disord 2000, 27: I-20.

18. Tauscher J, Pirker W, Willeit M, de Zwaan M, Bailer U, Neumeister A, Asenbaum S, Lennkh C, Praschak-Rieder N, Brucke T, Kasper S: [I23I] beta-CIT and single photon emission computed tomography reveal reduced brain serotonin transporter availability in bulimia nervosa. Biol Psychiatry 2001, 49:326-332.

19. Kuikka JT, Tammela L, Karhunen L, Rissanen A, Bergstrom KA, Naukkarinen H, Vanninen E, Karhu J, Lappalainen R, Repo-Tiihonen E, Tiihonen J, Uusitupa M: Reduced serotonin transporter binding in binge eating women. Psychopharmacology 200I, I 55:310-314.

20. Tiihonen J, Keski-Rahkonen A, Lopponen M, Muhonen M, Kajander J, Allonen T, Nagren K, Hietala J, Rissanen A: Brain serotonin I A receptor binding in bulimia nervosa. Biol Psychiatry 2004, 55:87|-873.

21. Bailer UF, Price JC, Meltzer CC, Mathis CA, Frank GK, Weissfeld L, McConaha CW, Henry SE, Brooks-Achenbach S, Barbarich NC, Kaye $\mathrm{WH}$ : Altered 5-HT(2A) receptor binding after recovery from bulimia-type anorexia nervosa: relationships to harm avoidance and drive for thinness. Neuropsychopharmacology 2004, 29: | |43-I| 55 . 
22. Oya S, Choi SR, Hou C, Mu M, Kung MP, Acton PD, Siciliano M, Kung HF: 2-((2-((dimethylamino)methyl)phenyl)thio)-5-iodophenylamine (ADAM): an improved serotonin transporter ligand. Nucl Med Biol 2000, 27:249-254.

23. Catafau AM, Perez V, Penengo MM, Bullich S, Danus M, Puigdemont D, Corripio I, Pascual C, Perich X, Alvarez E: SPECT of serotonin transporters using I23I-ADAM: optimal imaging time after bolus injection and long-term test-retest in healthy volunteers. J Nucl Med 2005, 46: I 301-I 309.

24. Erlandsson K, Sivananthan T, Lui D, Spezzi A, Townsend CE, Mu S, Lucas R, Warrington S, Ell PJ: Measuring SSRI occupancy of SERT using the novel tracer [I 23I]ADAM: a SPECT validation study. Eur J Nucl Med Mol Imaging 2005, 32: I 329-I 336.

25. Kauppinen TA, Bergström KA, Heikman P, Hiltunen J, Ahonen AK Biodistribution and radiation dosimetry of (I 23-I)-ADAM in healthy human subjects: preliminary results. Eur J Nud Med Mol Imaging 2003, 30:132-136.

26. Newberg AB, PlossI K, Mozley PD, Stubbs JB, Wintering N, Udeshi M Alavi A, Kauppinen T, Kung HF: Biodistribution and imaging with ( I 23)I-ADAM: a serotonin transporter imaging agent. J Nucl Med 2004, 45:834-84I.

27. Kauppinen TA, Koskela A, Diemling M, Keski-Rahkonen A, Sihvola E, Ahonen A: Comparison of manual and automated quantification methods of [I 23I]ADAM. Nuklearmedizin 2005, 44:205-2I 2.

28. Kaprio J, Pulkkinen L, Rose RJ: Genetic and environmental factors in health-related behaviors: studies on Finnish twins and twin families. Twin Res 2002, 5:366-37I.

29. First MB, Spitzer RL, Gibbon M, Williams JBW: Structured Clinical Interview for DSM-IV Axis I and Axis II Disorders New York.: Biometrics Research Department, New York State Psychiatric Institute; 1997.

30. Keski-Rahkonen A, Sihvola E, Raevuori A, Kaukoranta J, Bulik CM, Hoek HW, Rissanen A, Kaprio J: Reliability of self-reported eating disorders: Optimizing population screening. Int J Eat Disord 2006, 39:754-62.

31. Anderluh MB, Tchanturia K, Rabe-Hesketh S, Treasure J: Childhood obsessive-compulsive personality traits in adult women with eating disorders: defining a broader eating disorder phenotype. Am J Psychiatry 2003, I 60:242-247

32. Bucholz KK, Cadoret R, Cloninger CR, Dinwiddie SH, Hesselbrock VM, Nurnberger JI Jr, Reich T, Schmidt I, Schuckit MA: A new, semistructured psychiatric interview for use in genetic linkage studies: a report on the reliability of the SSAGA. I Stud Alcohol 1994, 55:149-158.

33. Wade T, Heath AC, Abraham S, Treloar SA, Martin NG, Tiggemann $M$ : Assessing the prevalence of eating disorders in an Australian twin population. Aust N Z J Psychiatry 1996, 30:845-85 I.

34. Backstrom I, Bergstrom M, Marcusson J: High affinity [3H]paroxetine binding to serotonin uptake sites in human brain tissue. Brain Res 1989, 486:261-268.

35. Frokjaer VG, Pinborg LH, Madsen J, deNijs R, Knudsen GM: Evaluation of the Serotonin Transporter Ligand [I-I 23]ADAM for SPECT Studies in Humans [abstract]. In Annales Universitatis Turkuensis D 660: Turku PET symposium 2005 Edited by: Nyman M], Oikonen V, Turiceanu M, Scheinen H. Turku, Turun Yliopisto; 2005:78.

36. Kaye WH, Frank GK, Bailer UF, Henry SE, Meltzer CC, Price JC, Mathis CA, Wagner A: Serotonin alterations in anorexia and bulimia nervosa: new insights from imaging studies. Physiol Behav 2005, 85:73-8I.

37. Uher R, Murphy T, Friederich HC, Dalgleish T, Brammer MJ, Giampietro V, Phillips ML, Andrew CM, Ng VW, Williams SC, Campbell IC, Treasure J: Functional neuroanatomy of body shape perception in healthy and eating-disordered women. Biol Psychiatry 2005, 58:990-997.

38. Walsh BT: Fluoxetine treatment of bulimia nervosa. J Psychosom Res 1991:33-40.

39. Vaswani M, Linda FK, Ramesh S: Role of selective serotonin reuptake inhibitors in psychiatric disorders: a comprehensive review. Prog Neuropsychopharmacol Biol Psychiatry 2003 27:85-102.

40. Fuller RW: Pharmacologic modification of serotonergic function: drugs for the study and treatment of psychiatric and other disorders. J Clin Psychiatry 1986, 47(Suppl):4-8.

4I. Gonzalez-Heydrich J, Peroutka SJ: Serotonin receptor and reuptake sites: pharmacologic significance. I Clin Psychiatry 1990, 5 I (Suppl):5- I2.
42. Goodwin GM: How do antidepressants affect serotonin receptors? The role of serotonin receptors in the therapeutic and side effect profile of the SSRIs. J Clin Psychiatry 1996, 57(Suppl 4):9-13.

43. Stahl SM: Mechanism of action of serotonin selective reuptake inhibitors. Serotonin receptors and pathways mediate therapeutic effects and side effects. J Affect Disord I998, 5 I:2 I5-235.

44. Petty F, Davis LL, Kabel D, Kramer GL: Serotonin dysfunction disorders: a behavioral neurochemistry perspective. J Clin Psychiatry 1996, 57(Suppl 8): I I- I6.

45. Coyle JT, Duman RS: Finding the intracellular signaling pathways affected by mood disorder treatments. Neuron 2003 , 38: I57-160.

46. Reba L, Thornton L, Tozzi F, Klump KL, Brandt H, Crawford S, Crow S, Fichter MM, Halmi KA, Johnson C, Kaplan AS, Keel P, LaVia M, Mitchell J, Strober M, Woodside DB, Rotondo A, Berrettini WH, Kaye WH, Bulik CM: Relationships between features associated with vomiting in purging-type eating disorders. Int J Eat Disord 2005, 38:287-294.

47. Innis R, Baldwin R, Sybirska E, Zea Y, Laruelle M, al-Tikriti M, Charney D, Zoghbi S, Smith E, Wisniewski G: Single photon emission computed tomography imaging of monoamine reuptake sites in primate brain with [I23I]CIT. Eur J Pharmacol 199I, 200:369-370.

48. Laruelle M, Baldwin RM, Malison RT, Zea-Ponce Y, Zoghbi SS, alTikriti MS, Sybirska EH, Zimmermann RC, Wisniewski G, Neumeyer JL: SPECT imaging of dopamine and serotonin transporters with [123I]beta-CIT: pharmacological characterization of brain uptake in nonhuman primates. Synapse 1993, I 3:295-309.

49. Neumeyer JL, Tamagnan G, Wang S, Gao Y, Milius RA, Kula NS, Baldessarini RJ: $\mathbf{N}$-substituted analogs of 2 beta-carbomethoxy-3 beta-(4'-iodophenyl)tropane (beta-CIT) with selective affinity to dopamine or serotonin transporters in rat forebrain. Med Chem 1996, 39:543-548.

50. Ramamoorthy S, Blakely RD: Phosphorylation and sequestration of serotonin transporters differentially modulated by psychostimulants. Science 1999, 285:763-766.

5I. Milak MS, Ogden RT, Vinocur DN, Van Heertum RL, Cooper TB, Mann IJ, Parsey RV: Effects of tryptophan depletion on the binding of [I IC]-DASB to the serotonin transporter in baboons: response to acute serotonin deficiency. Biol Psychiatry 2005, 57:102-106.

52. Talbot PS, Frankle WG, Hwang DR, Huang $Y$, Suckow RF, Slifstein $M$, Abi-Dargham A, Laruelle M: Effects of reduced endogenous 5 $H T$ on the in vivo binding of the serotonin transporter radioligand IIC-DASB in healthy humans. Synapse 2005, 55:164-175.

53. Lundquist $P$, Roman $M$, Syvanen $S$, Hartvig $P$, Blomquist $G$, Hamma rlund-Udenaes $M$, Langstrom $B$ : Effect on [(I I)C]DASB binding after tranylcypromine-induced increase in serotonin concentration: Positron emission tomography studies in monkeys and rats. Synapse 2007, $61: 440-449$.

54. Wihlback AC, Sundstrom Poromaa I, Bixo M, Allard P, Mjorndal T, Spigset O: Influence of menstrual cycle on platelet serotonin uptake site and serotonin $2 \mathrm{~A}$ receptor binding. Psychoneuroendocrinology 2004, 29:757-766.

55. Best SE, Sarrel PM, Malison RT, Laruelle M, Zoghbi SS, Baldwin RM, Seibyl JP, Innis RB, van Dyck CH: Striatal dopamine transporter availability with [I23I]beta-CIT SPECT is unrelated to gender or menstrual cycle. Psychopharmacology 2005, I83:|8|-I89.

\section{Pre-publication history}

The pre-publication history for this paper can be accessed here:

\section{http://www.biomedcentral.com/1471-244X/7/19/pre} $\underline{\mathrm{pub}}$ 